\title{
Endocrine abnormalities in ring chromosome 11: a case report and review of the literature
}

\author{
Renata Lange ${ }^{1, *}$, Caoê Von Linsingen ${ }^{1, *}$, Fernanda Mata', Aline Barbosa Moraes ${ }^{2}$, \\ Mariana Arruda ${ }^{2}$ and Leonardo Vieira Neto ${ }^{1,2}$ \\ ${ }^{1}$ Endocrine Section, Hospital Federal da Lagoa, Rio de Janeiro, Brazil \\ ${ }^{2}$ Department of Internal Medicine and Endocrine Section, Medical School and Hospital Universitário Clementino \\ Fraga Filho, Universidade Federal de Rio de Janeiro, Rua Prof. Rodolpho Paulo Rocco, 255, 9th Floor, Ilha do Fundão, \\ Rio de Janeiro 21941-913, Brazil \\ *(R Lange and C Von Linsingen contributed equally to this work)
}

\author{
Correspondence \\ should be addressed \\ to L Vieira Neto \\ Email \\ netolv@gmail.com
}

\section{Summary}

Ring chromosomes (RCs) are uncommon cytogenetic findings, and RC11 has only been described in 19 cases in the literature. Endocrine abnormalities associated with RC11 were reported for two of these cases. The clinical features of RC11 can result from an alteration in the structure of the genetic material, ring instability, mosaicism, and various extents of genetic material loss. We herein describe a case of RC11 with clinical features of 11q-syndrome and endocrine abnormalities that have not yet been reported. A 20-year-old female patient had facial dysmorphism, short stature, psychomotor developmental delays, a ventricular septal defect, and thrombocytopenia. Karyotyping demonstrated RC11 (46,XX,r(11)(p15q25)). This patient presented with clinical features that may be related to Jacobsen syndrome, which is caused by partial deletion of the long arm of chromosome 11. Regarding endocrine abnormalities, our patient presented with precocious puberty followed by severe hirsutism, androgenic alopecia, clitoromegaly, and amenorrhea, which were associated with overweight, type 2 diabetes mellitus (T2DM), and hyperinsulinemia; therefore, this case meets the diagnostic criteria for polycystic ovary syndrome. Endocrine abnormalities are rare in patients with RC11, and the association of RC11 with precocious puberty, severe clinical hyperandrogenism, insulin resistance, and T2DM has not been reported previously. We speculate that gene(s) located on chromosome 11 might be involved in the pathogenesis of these conditions. Despite the rarity of RCs, studies to correlate the genes located on the chromosomes with the phenotypes observed could lead to major advances in the understanding and treatment of more prevalent diseases.

\section{Learning points:}

- We hypothesize that the endocrine features of precocious puberty, severe clinical hyperandrogenism, insulin resistance, and T2DM might be associated with 11q-syndrome.

- A karyotype study should be performed in patients with short stature and facial dysmorphism.

- Early diagnosis and adequate management of these endocrine abnormalities are essential to improve the quality of life of the patient and to prevent other chronic diseases, such as diabetes and its complications.

\section{Background}

Reports of ring chromosome 11 (RC11) are rare. To the best of our knowledge, only 19 cases have been described in the literature (Table 1). The clinical characteristics of these patients are highly variable due to RC instability, mosaicism, and variable extents of genetic material loss, followed by terminal deletion in one or both chromosome arms (1) (2) (3) (4) (5) (6) (7) (8) (9) (10) (11) (12). 

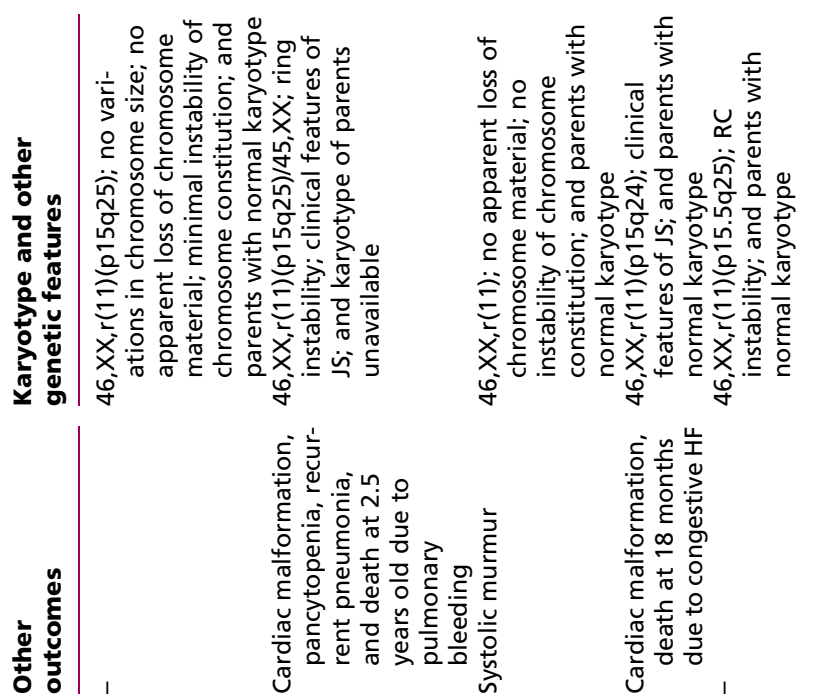
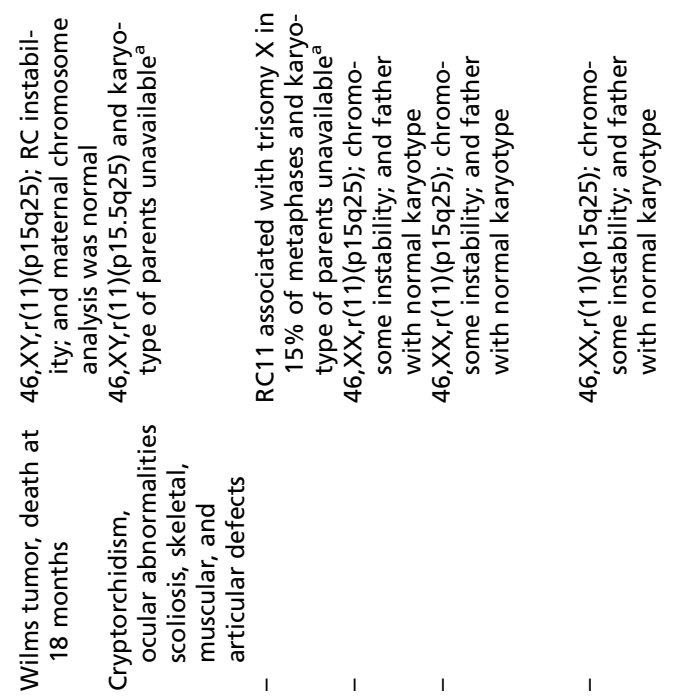
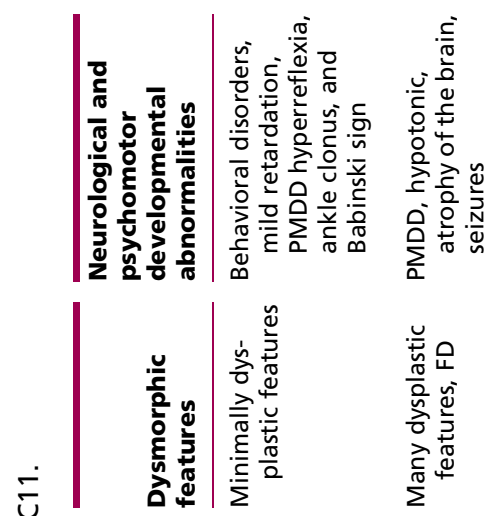

$\overline{\bar{z}}$
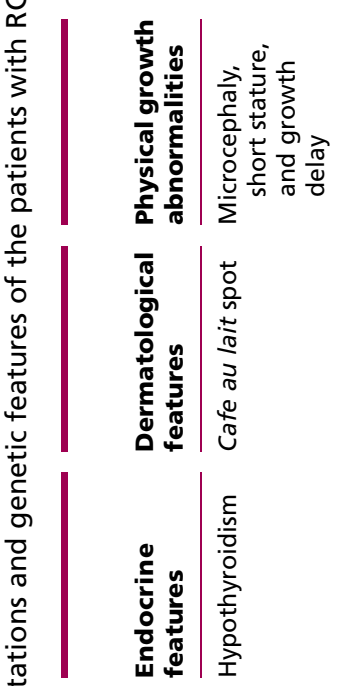

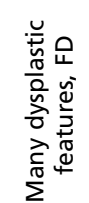

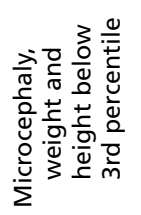

운

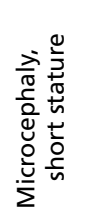

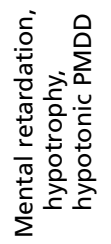
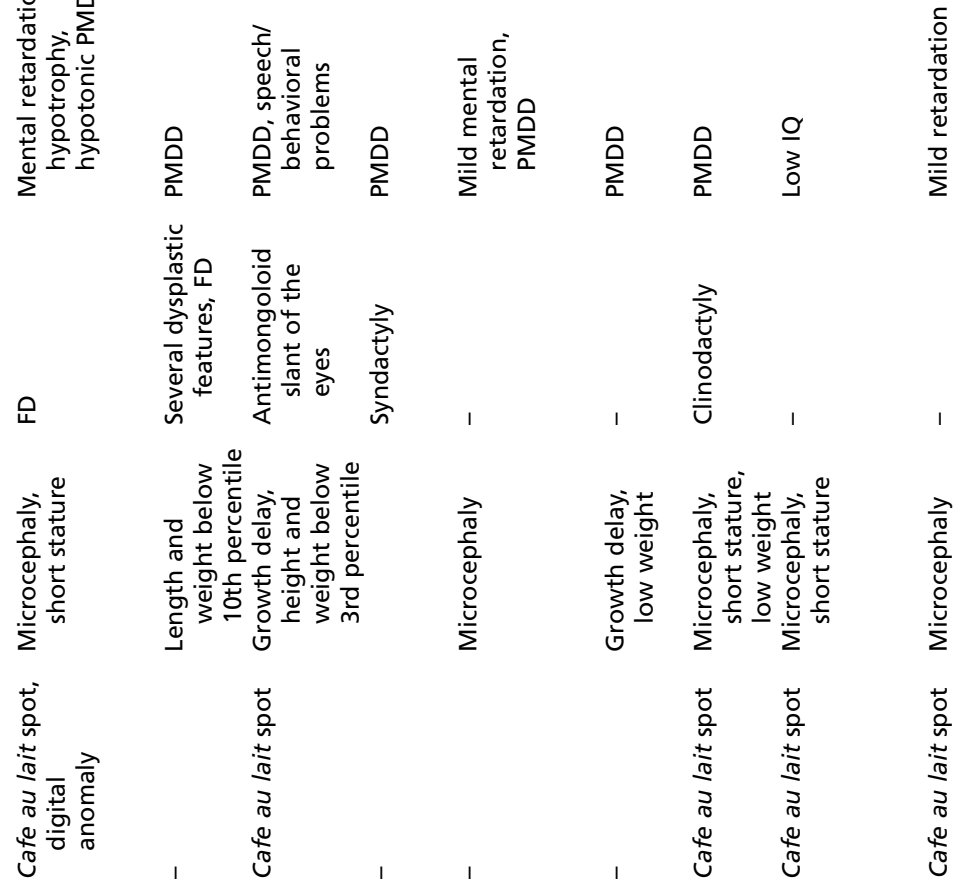

$$
\begin{aligned}
& \frac{0}{0} \\
& \frac{0}{0} \\
& \frac{\pi}{\pi} \\
& \frac{\pi}{0} \\
& \frac{0}{0} \\
& \frac{0}{0}
\end{aligned}
$$
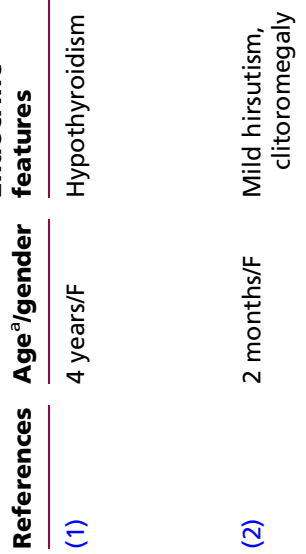
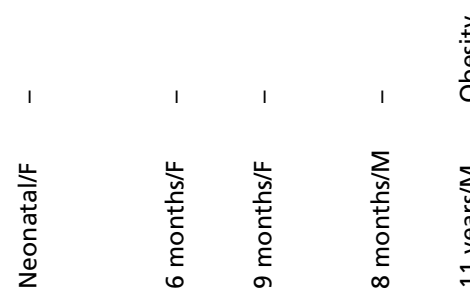

$\stackrel{0}{6}$

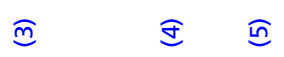

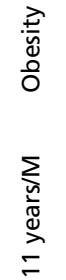<smiles>COC(=O)O</smiles>

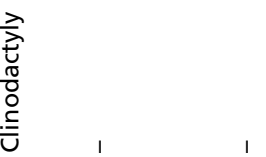
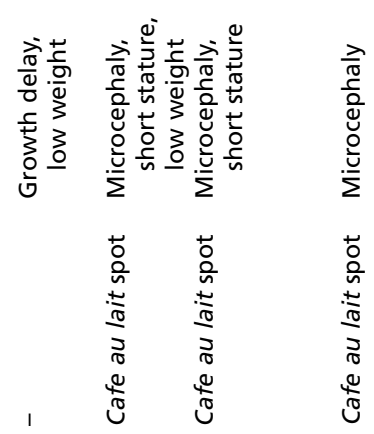

$\widehat{\Xi}$

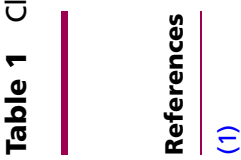

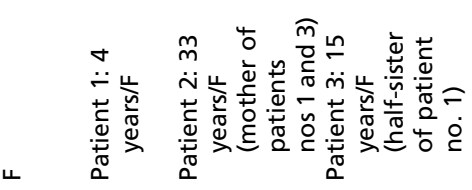




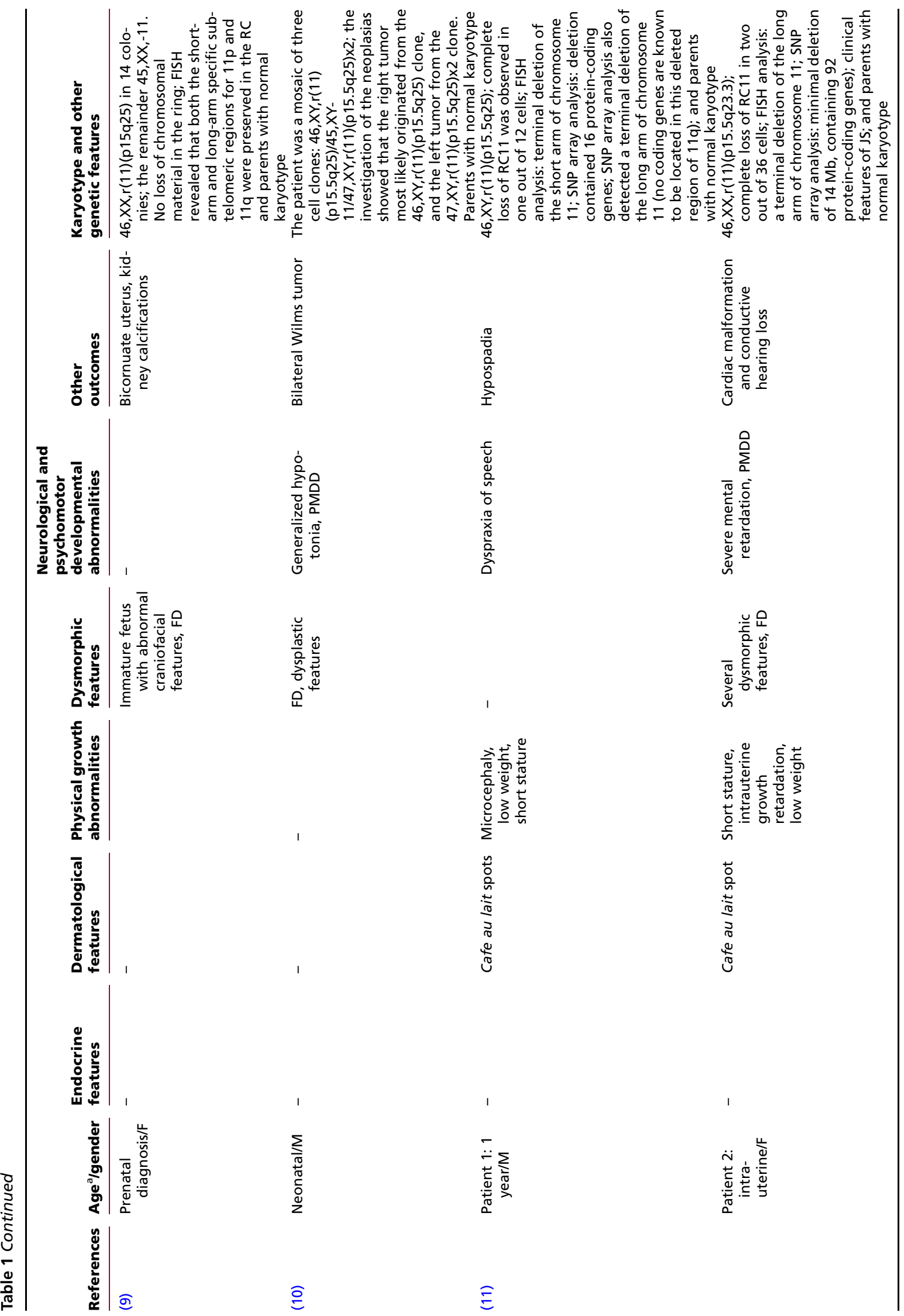




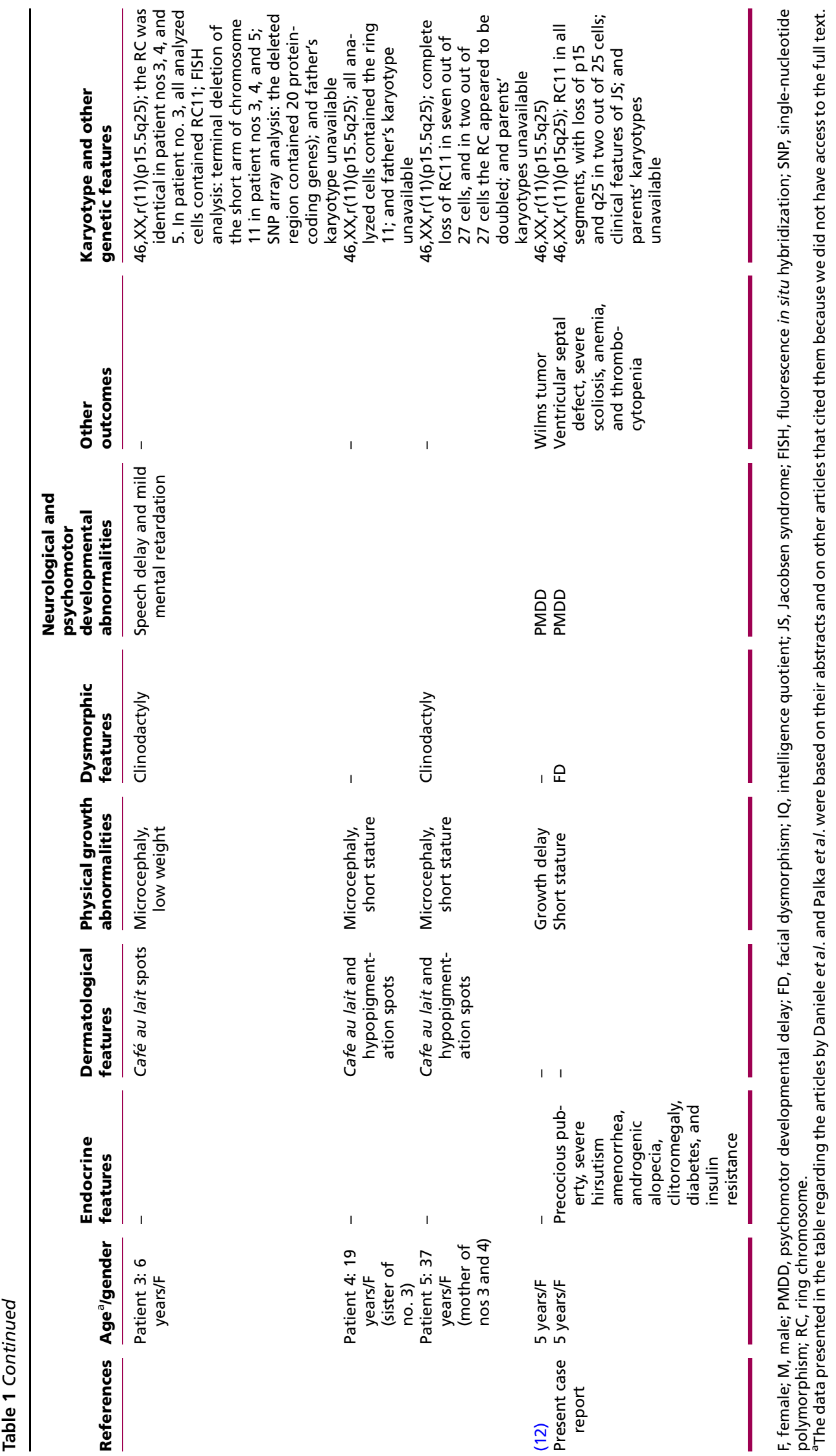


In some cases, patients with RC presented features of Jacobsen syndrome (JS), also known as 11q-syndrome. These cases were caused by a partial deletion of the long arm of chromosome 11 (13). The most common clinical features of 11q-syndrome are a growth delay, psychomotor developmental delay (PMDD), and dysmorphic facial features (13). The hormonal changes previously described in patients with JS include hypothyroidism and growth hormone (GH) deficiency (13) (14) (15).

We herein describe a case of RC11 with clinical features of 11q-syndrome and endocrine abnormalities that have not previously been reported for this condition.

\section{Case presentation}

A 20-year-old female patient was referred to our Endocrinology Service for an evaluation of hirsutism, which started at age 5, and a 5-month history of amenorrhea. She was not using any medications. A physical examination revealed hirsutism (26 points in the Ferriman and Gallwey scale), androgenic alopecia, and clitoromegaly. Her height was below the third percentile, her BMI was $26.7 \mathrm{~kg} / \mathrm{m}^{2}$, and she had normal blood pressure. There were no signs of increased muscle mass or hoarseness. She presented with a pan-systolic murmur on auscultation.

The patient was the firstborn child to her 25-year-old mother and 32-year-old father, who were non-consanguineous. She was born by a normal vaginal delivery at term following a normal pregnancy. Her birth weight was $1700 \mathrm{~g}$ and she was $38 \mathrm{~cm}$ long. Interventricular communication of the membranous septum was diagnosed at birth, but surgery was not indicated. The patient presented with a delay in speech and walking, as well as poor school performance. She required a blood transfusion at age 4 because of severe anemia and thrombocytopenia, and she had undergone four orthopedic surgeries since the age of 14 to correct severe scoliosis.

\section{Investigation}

At age 5, the patient underwent a genetic evaluation due to short stature and facial dysmorphism (a high prominent forehead, facial asymmetry, trigonocephaly, asymmetrically set ears, and retrognathia), which demonstrated RC11. Twenty-five metaphases were analyzed by GTG banding, which revealed the presence of RC11 in all segments and a loss of p15 and q25 in two segments $(46, X X, r(11)(p 15 q 25))$. At that time, the results of a hormonal evaluation (somatotrophic and thyroid axes) were normal. At age 7 , she presented with precocious puberty. At this time, hormonal blocking with a gonadotropin-releasing hormone analogue was initiated and continued from 8 to 11 years of age. She experienced menarche at age 12 . These evaluations and treatments were performed at another institution.

At age 13, the patient underwent an investigation for hirsutism, which revealed normal levels of DHEA-S, androstenedione, testosterone, estradiol $\left(\mathrm{E}_{2}\right)$, and thyroidstimulating hormone (TSH). She had high levels of fasting plasma glucose ((FPG): $138 \mathrm{mg} / \mathrm{dl}$; normal range (NR): 70-99)) and insulin (24.8 U/ml). A pelvic ultrasound examination was unremarkable, except for a borderline ovarian volume of $10 \mathrm{ml}$. The patient experienced significant weight gain after the age of 15 .

At age 20, a laboratory evaluation in our unit showed normal levels of androstenedione $(1.11 \mathrm{mmol} / \mathrm{l}$; NR: 0.33.3), total testosterone ( $41 \mathrm{ng} / \mathrm{dl}$; NR: $10-75)$, and DHEA-S (237.5 ng/ml; NR: 148-407) but dihydrotestosterone levels were elevated (437.5 pg/ml; NR: 23-368). TSH (1.34 $\mu \mathrm{UI} / \mathrm{ml}$; NR: 0.3-5.0) and prolactin (21.1 ng/ml; NR: <23) levels were normal. Cushing's syndrome and congenital adrenal hyperplasia were excluded by a normal overnight suppression $1 \mathrm{mg}$ dexamethasone test (cortisol: $0.4 \mu \mathrm{g} / \mathrm{dl}$; normal suppression <1.8) and normal levels of 17-hydroxyprogesterone $(94 \mathrm{ng} / \mathrm{dl}$; NR: <200) respectively. No signs or symptoms of acromegaly were present. She presented with high levels of FPG (138 mg/dl), HbA1c (7.3\%; NR: <5.8\%), insulin $(26 \mathrm{U} / \mathrm{ml})$, and she had insulin resistance, as assessed by the homeostatic assay (HOMA-IR; 9.82). There was mild thrombocytopenia with normal remaining hematological series. The lipid profile was normal.

\section{Outcome and follow-up}

Treatment was started with $1500 \mathrm{mg} /$ day of metformin, $0.035 \mathrm{mg}$ of ethinyl estradiol combined with cyproterone acetate $(1 \mathrm{mg}), 5 \mathrm{mg} /$ day finasteride, and a hair lotion containing $17 \alpha-\mathrm{E}_{2}$. Spironolactone was administered at an initial dose of $25 \mathrm{mg}$ in the first month and was progressively increased up to $100 \mathrm{mg}$ /day according to the tolerance of the patient.

After 6 months, the patient presented with adequate glycemic control (HbA1c: 5.3\%), a weight reduction of $4.3 \mathrm{~kg}$ in 4 months, substantial improvement of alopecia, and a slow hair growth rate.

\section{Discussion}

We herein presented the case of a patient with RC11 with clinical features of 11q-syndrome such as facial 
dysmorphism, growth delay, PMDD, congenital heart malformation, and thrombocytopenia. She also presented with precocious puberty, severe clinical hyperandrogenism, insulin resistance, and type 2 diabetes mellitus (T2DM). Such conditions have not yet been reported in RC11.

To the best of our knowledge, there have only been 19 cases of constitutional RC11 described in the literature. In our review of these cases, we observed a large variety of phenotypes among the patients. This variety might be explained by the size of the terminal deletion (at the short or long arm), mitotic instability, and the potential mosaic distribution of the RC (16). Only two studies in patients with RC11 (10) (11) used high-resolution genome-wide array techniques; therefore, it is difficult to establish a genotype-phenotype relationship. Table 1 shows the clinical manifestations of the cases reported so far.

JS is caused by a partial deletion of 11q, which is compatible with the present patient's karyotype. JS has already been reported in five patients with RC11 (2) (3) (4) (7) (11) (Table 1) with different degrees of severity. Our patient presented with the main manifestations of JS including facial dysmorphism, growth delay, PMDD, congenital heart malformation, and thrombocytopenia. The latter is a component of the Paris-Trousseau syndrome, a hematological disorder that has been reported in at least $88.5 \%$ of cases with JS and suggests the diagnosis of JS in patients with few clinical features of the syndrome (13) Only two cases of RC11 (2), including our present case, manifested these hematological alterations. There is no clear correlation between the size of the deletion and the phenotype (13). In fact, the correlation of the size of the deletion with the phenotype appears to be variable and depends on the location of the breakpoint. Although most of the cases shown in Table 1 fell within the same chromosomal band level, the breakpoint might have varied at the base pair level.

Regarding endocrine disorders in patients with RC11, Valente et al. (1) described hypothyroidism diagnosed in a 3-month-year-old girl that was confirmed at age 1 (based on low thyroxine and elevated TSH levels), and Niikawa et al. (2) reported on a 2-year-old patient with mild hirsutism and clitoromegaly who died at the age of 2 years and 6 months with no reported hormonal profile. Hypothyroidism and GH deficiency were both reported in the two patients with JS (13) (15).

Our patient met the diagnostic criteria for polycystic ovarian syndrome (PCOS) (17) because she presented with clinical hyperandrogenism (hirsutism, androgenic alopecia) and chronic anovulation (amenorrhea), although ovulatory dysfunction is difficult to assess accurately. Because PCOS is a diagnosis of exclusion, several conditions that mimic PCOS were excluded, such as thyroid disease, Cushing's syndrome, hyperprolactinemia, congenital adrenal hyperplasia, androgen-secreting tumors, acromegaly, and hirsutism due to medications or illicit drugs. Except for clitoromegaly, no other feature of an androgen-secreting tumor was found (i.e. rapid onset of a change in voice and gain in muscle mass). In fact, the serum testosterone and DHEAS levels were normal. The clitoromegaly could be explained by elevated dihydrotestosterone levels in sensitive peripheral target tissues (18). Niikawa et al. (2) also found clitoromegaly in their case report. Elevated dihydrotestosterone levels may have reflected a higher activity of $5 \alpha$-reductase in our patient. In the review of the literature, we found no association between chromosome 11 deletions and changes in $5 \alpha$-reductase activity. Other common features of PCOS, such as T2DM, overweight, and hyperinsulinemia, were also present.

Multiple biochemical pathways and several genes are related to the pathogenesis of PCOS; however, the etiology of PCOS is multifactorial, and finding a single gene responsible for the syndrome is unlikely. We hypothesized that genes located on chromosome 11 might be involved in the pathogenesis of the syndrome. It is known that hyperinsulinemia plays a central role in the pathogenesis of PCOS (17). Polymorphisms of the KCNJ11 (Kir6.2) and ABCC8 (SUR 1) genes located at 11p15.1 may confer greater susceptibility to T2DM and have been reported to be associated with disorders of insulin secretion (19). Additionally, the variable number of tandem repeats (VNTR) locus (on chromosome 11p15.5) upstream of the insulin gene (INS) regulates insulin expression. Waterwort et al. (20) demonstrated a link between PCOS and the INS VNTR locus. The deletion of these genes, or even the involvement of chromosome 11 in our patient, could explain the metabolic disturbances.

In most of the reported cases, the parental chromosomes were normal. Two series reported the presence of RC11 in first-degree relatives (8)(11), but most cases of RC are sporadic (16). In our case, the patient's parents were phenotypically normal, but a karyotype examination was not performed. However, given the absence of any clinical and/or laboratory characteristics of the syndrome, it is unlikely that the patient's parents have any chromosomal abnormalities. Most authors (1) (3) (4) (5) (8) (9) (10) (11) (Table 1) have described patients with RC11 whose parents presented with normal karyotypes. 


\section{Conclusions}

RC11 is an extremely rare genetic disorder with very few cases described in the literature and a highly variable clinical presentation. We have herein described a case of RC11 that presented with precocious puberty, severe clinical hyperandrogenism, insulin resistance, and T2DM, which is an association that has not yet been reported. Despite the rarity of RCs, studies to correlate the genes located on the chromosomes with the phenotypes observed could lead to major advances in the understanding and treatment of more prevalent diseases.

\section{Declaration of interest}

The authors declare that there is no conflict of interest that could be perceived as prejudicing the impartiality of the research reported.

\section{Funding}

This research did not receive any specific grant from any funding agency in the public, commercial or not-for-profit sector.

\section{Patient consent}

Written informed consent was obtained from the patient for publication of this case report and any accompanying images.

\section{Author contribution statement}

Study design: L Vieira Neto; Study conduct: L Vieira Neto and R Lange; Literature review: R Lange, C Von Linsingen, F Mata, A B Moraes, M Arruda, and L Vieira Neto; Data collection: R Lange, C Von Linsingen, and F Mata; Data analysis: L Vieira Neto; Data interpretation: L Vieira Neto, M Arruda, A B Moraes, R Lange, C Von Linsingen, and F Mata; Drafting manuscript: R Lange, C Von Linsingen, F Mata, A B Moraes, M Arruda, and L Vieira Neto; Revising manuscript contents: LVieira Neto, M Arruda, A B Moraes, R Lange, $C$ Von Linsingen, and F Mata; Approving final version of manuscript: LVieira Neto, M Arruda, A B Moraes, R Lange, C Von Linsingen, F Mata; Integrity of the data analysis: L Vieira Neto, and M Arruda.

\section{References}

1 Valente M, Muller H \& Sparkes RS 1977 Ring 11 chromosome (46,xx, r11(p15q25)). Human Genetics 36 345-350. (doi:10.1007/BF00446287)

2 Niikawa N, Jinno Y, Tomiyasu T, Fukushima Y \& Kudo K 1981 Ring chromosome 11 [46,XX,r(11) (p15q25)] associated with clinical features of the 11q-syndrome. Annales de Génétique 24 172-175.

3 Retbi JM, Raoul O, Allemon MC \& Dayras JC 1981 Ring-shaped chromosome 11 (46, XX, r11). A new case. La Nouvelle Presse Médicale 10181.

4 Cousineau AJ, Higgins JV, Scott-Emuakpor AB \& Mody G 1983 Brief clinical report: Ring-11 chromosome: phenotype-karyotype correlation with deletions of 11q. American Journal of Medical Genetics 14 29-35. (doi:10.1002/ajmg.1320140106)
5 Romain DR, Gebbie OB, Parfitt RG, Columbano-Green LM, Smythe RH, Chapman CJ \& Kerr A 1983 Two cases of ring chromosome 11. Journal of Medical Genetics 20 380-382. (doi:10.1136/jmg.20.5.380)

6 Daniele S, Pecorelli F, Tiepolo L, Armellini R \& Liotti FS 1986 Congenital ocular and other systemic abnormalities associated with ring-11 chromosome. Graefe's Archive for Clinical and Experimental Ophthalmology 224 317-320. (doi:10.1007/BF02143078)

7 Palka G, Verrotti A, Peca S, Mosca L, Lombardo G, Verrotti M \& Morgese G 1986 Ring chromosome 11. A case report and review of the literature. Annales de Génétique 29 55-58.

8 Fagan K, Suthers GK \& Hardacre G 1988 Ring chromosome 11 and cafe-au-lait spots. American Journal of Medical Genetics 30 911-916. (doi:10.1002/ajmg.1320300406)

9 Mohamed AN, Ebrahim SA, Aatre R, Qureshi F, Jacques SM \& Evans MI 2001 Prenatal diagnosis of a de novo ring chromosome 11. American Journal of Medical Genetics 102 368-371. (doi:10.1002/ajmg.1492)

10 Carella M, Spreafico F, Palumbo O, Storlazzi CT, Tabano S, Miozzo M, Miglionico L, Calvano S, Sindici G, Gamba B et al 2010 Constitutional ring chromosome 11 mosaicism in a Wilms tumor patient: cytogenetic, molecular and clinico-pathological studies. American Journal of Medical Genetics. Part A 152A 1756-1763. (doi:10.1002/ajmg.a.33420)

11 Hansson KB, Gijsbers AC, Oostdijk W, Rehbock JJ, de Snoo F, Ruivenkamp CA \& Kant SG 2012 Molecular and clinical characterization of patients with a ring chromosome 11. European Journal of Medical Genetics 55 708-714. (doi:10.1016/j.ejmg.2012.08.004)

12 Zhang H, Feng C \& Tang SQ 2012 Wilms' tumor and ring chromosome 11 in a child. Zhongguo Dang Dai Er Ke Za Zhi 14 993-994.

13 Mattina T, Perrotta CS \& Grossfeld P 2009 Jacobsen syndrome. Orphanet Journal of Rare Diseases 4 9. (doi:10.1186/1750-1172-4-9)

14 Haghi M, Dewan A, Jones KL, Reitz R, Jones C \& Grossfeld P 2004 Endocrine abnormalities in patients with Jacobsen (11q-) syndrome. American Journal of Medical Genetics. Part A 129A 62-63. (doi:10.1002/ ajmg.a.30248)

15 Pivnick EK, Velagaleti GV, Wilroy RS, Smith ME, Rose SR, Tipton RE \& Tharapel AT 1996 Jacobsen syndrome: report of a patient with severe eye anomalies, growth hormone deficiency, and hypothyroidism associated with deletion 11 (q23q25) and review of 52 cases. Journal of Medical Genetics 33 772-778. (doi:10.1136/jmg.33.9.772)

16 Kosztolanyi G, Mehes K \& Hook EB 1991 Inherited ring chromosomes: an analysis of published cases. Human Genetics 87 320-324. (doi:10.1007/BF00200912)

17 Legro RS, Arslanian SA, Ehrmann DA, Hoeger KM, Murad MH, Pasquali R, Welt CK \& Endocrine S 2013 Diagnosis and treatment of polycystic ovary syndrome: an Endocrine Society clinical practice guideline. Journal of Clinical Endocrinology and Metabolism 98 4565-4592. (doi:10.1210/jc.2013-2350)

18 Auchus RJ 2004 The backdoor pathway to dihydrotestosterone. Trend in Endocrinology and Metabolism 15 432-438. (doi:10.1016/j.tem.2004. 09.004)

19 Laukkanen O, Pihlajamaki J, Lindstrom J, Eriksson J, Valle TT, Hamalainen H, Ilanne-Parikka P, Keinanen-Kiukaanniemi S, Tuomilehto J, Uusitupa M et al 2004 Polymorphisms of the SUR1 (ABCC8) and Kir6.2 (KCNJ11) genes predict the conversion from impaired glucose tolerance to type 2 diabetes. The Finnish Diabetes Prevention Study. Journal of Clinical Endocrinology and Metabolism 89 6286-6290. (doi:10.1210/jc.2004-1204)

20 Waterworth DM, Bennett ST, Gharani N, McCarthy MI, Hague S, Batty S, Conway GS, White D, Todd JA, Franks S et al 1997 Linkage and association of insulin gene VNTR regulatory polymorphism with polycystic ovary syndrome. Lancet 349 986-990. (doi:10.1016/ S0140-6736(96)08368-7)

Received in final form 23 September 2015

Accepted 15 October 2015 